\title{
Pragmatism and the Birth of Subjective Probability
}

\author{
Maria Carla Galavotti
}

\section{(2) OpenEdition}

Journals

Electronic version

URL: http://journals.openedition.org/ejpap/1509

DOI: 10.4000/ejpap.1509

ISSN: 2036-4091

\section{Publisher}

Associazione Pragma

\section{Electronic reference}

Maria Carla Galavotti, «Pragmatism and the Birth of Subjective Probability », European Journal of Pragmatism and American Philosophy [Online], XI-1 | 2019, Online since 19 July 2019, connection on 21 July 2019. URL : http://journals.openedition.org/ejpap/1509; DOI : 10.4000/ejpap.1509

This text was automatically generated on 21 July 2019

\section{(c) $($ i) $(9)$}

Author retains copyright and grants the European Journal of Pragmatism and American Philosophy right of first publication with the work simultaneously licensed under a Creative Commons AttributionNonCommercial-NoDerivatives 4.0 International License. 


\title{
Pragmatism and the Birth of Subjective Probability
}

\author{
Maria Carla Galavotti
}

\section{Pragmatism and the Foundations of Probability}

1 The debate on the foundations of probability in the first half of the twentieth century is imbued with ideas that are distinctive of pragmatism. In earlier work, I have emphasized that a number of protagonists of that debate, regardless of the attitude taken in connection with the interpretation of probability, were strongly influenced by pragmatist philosophers. For example, Rudolf Carnap acknowledged his debt towards Clarence Irving Lewis, as did Hans Reichenbach and Frank Plumpton Ramsey in connection with Charles Sanders Peirce and William James, while Bruno de Finetti identified with the Italian pragmatists, especially Giovanni Vailati, his source of inspiration. Moreover, Ernest Nagel claimed to have borrowed the leading idea of his "truth-frequency" theory of probability from John Dewey. ${ }^{1}$

2 According to a widespread opinion, even before the encounter between logical empiricism and American pragmatism a number of European scientists including Ernst Mach, Ludwig Boltzmann, Henri Poincaré, Pierre Duhem, and Karl Pearson, had embraced a view of science with strong affinities to the pragmatist outlook. ${ }^{2}$ Their influence extended not only to the above mentioned authors, but also to others such as Richard von Mises, Janina Hosiasson, Harold Jeffreys, Émile Borel, and Maurice Fréchet, all of whom took part in the debate on the foundations of probability and heralded a probabilistic approach to epistemology revolving around the conviction that science, and knowledge at large, are probabilistic in nature, and that knowledge acquisition is obtained inductively from empirical data. Of the main interpretations of probability, namely frequentism, logicism, subjectivism and propensionism, subjectivism is the closest to the pragmatist perspective first and foremost for the centrality ascribed to man as an agent acting in the world, and the idea that human action is guided by belief. ${ }^{3}$ In what follows attention will be called to the influence of pragmatism, and more in particular European 
pragmatism, on the birth of subjective probability, concentrating on three of its major representatives in different countries, namely Borel, Ramsey and de Finetti.

Before embarking on that discussion, it is useful to highlight those aspects of the pragmatist outlook that are more relevant to our present purposes. In a recent paper called The Spirit of Pragmatism in the Quads of Oxford, David Backhurst identifies five major components of pragmatism, which can be summarized as follows: (1) a doxastic theory of truth as that which is deserving of belief; (2) an empiricist account of meaning - the meaning of an expression resides in its consequences for action; (3) a fallibilist, dynamic, inquiry centered account of knowledge; (4) an anti-dualistic approach according to which the distinction between theoretical and practical reasoning is rejected in favour of a unified conception of inquiry grounded in scientific method; (5) the primacy of practice (Backhurst 2017: 77-8). Focusing on the literature on the foundations of probability, the following tenets, which are obviously in tune with the features described by Backhurst, play a pivotal role: (1) knowledge is intrinsically probabilistic; (2) prediction is the primary purpose of science; (3) probability statements acquire meaning in connection with their capability to guiding decision and action; (4) the criterion for testing probabilistic evaluations and justifying inferential methods (induction) is success; (5) scientific truth corresponds to a special sort of belief, and results from consent in the long run. Although one or the other of these statements is shared by a number of supporters of different interpretations of probability, they constitute the gist of the subjective theory.

\section{The Subjective Theory}

4 Subjectivism is the theory that probability is the degree of belief actually held by someone in a state of uncertainty regarding the occurrence of an event. According to this approach, probability is a primitive notion endowed with a psychological foundation, which requires an operative definition specifying a way of measuring it. A longstanding method dating back to the seventeenth century is the betting scheme, according to which the degree of belief corresponds to the odds at which an agent would be willing to bet on an event whose occurrence is uncertain. The probability of such an event equals the price to be paid by the agent to obtain a certain gain should the event occur. The only requirement to be imposed to degrees of belief is coherence. Put in terms of betting, coherence ensures that betting ratios are chosen in such a way as to avoid sure loss, or gain, namely the situation known in the literature as a Dutch book. The strength of the notion of coherence amounts to the fact that the laws of probability are derivable from its assumption, or, in other words, coherent degrees of belief satisfy the rules of additive probabilities. This result, which lies at the core of the subjective theory, was stated for the first time by Ramsey in 1926, and demonstrated by de Finetti in 1928. Although the betting scheme is probably the best-known operative method that allows measurement of degrees of belief, it is by no means the only one; more on this will be said in what follows.

Since they were the first to realize the importance of coherence and its role within the subjective outlook, Ramsey and de Finetti are reputed to be the "fathers" of subjective probability. But they were by no means the only ones to embrace a subjective approach to probability, together with a probabilistic conception of knowledge and science. In the first half of the twentieth century, the same approach was shared by other authors in distant parts of Europe, including Janina Hosiasson, ${ }^{4}$ Émile Borel, and Paul Lévy. In 
addition, Harold Jeffreys, albeit embracing the logical theory of probability, heralded a view of epistemology in many ways close to subjectivism. ${ }^{5}$

\section{Frank Ramsey's Pragmatism}

Ramsey's pragmatism is broadly discussed in the literature, where he is deemed a pragmatist in connection with his conception of meaning, theories and scientific laws. ${ }^{6}$ His view of probability is just as imbued with pragmatist ideas, as he himself acknowledges by referring to James, and especially Peirce on whose writings he maintains that the final section of Truth and Probability is "almost entirely based" (Ramsey 1990: 90). ${ }^{7}$ The gist of Ramsey's pragmatism lies with the centrality of belief as our guide to action, which goes hand in hand with the stress put on predictive success, providing the criterion for evaluating probability assessments, and more generally for justifying induction. As put by Ramsey in Induction: Keynes and Wittgenstein: "a type of inference is reasonable or unreasonable according to the relative frequency with which it leads to truth and falsehood. Induction is reasonable because it produces predictions which are generally verified, not because of any logical relation between its premisses and conclusion." (Ramsey 1991: 301). The pragmatic flavor of this attitude is emphasized by Ramsey himself, who notices that "this is a kind of pragmatism: we judge mental habits by whether they work, i.e. whether the opinions they lead to are for the most part true, or more often true than those which alternative habits would lead to" (Ramsey 1990: 93). By taking such a stand Ramsey anticipates work by de Finetti, Savage, and subsequent subjective statisticians who developed a whole family of methods for the validation of probability assessments, like scoring rules. More on this in Section 4 below.

7 A peculiar trait of Ramsey's version of subjectivism is his definition of chance - which represents an important contribution to the subjective theory, surprisingly overlooked by the literature. ${ }^{8}$ Although endowed with objective import, Ramsey's notion of chance, together with the related notion of probability in physics, are framed within the subjective outlook. Contrary to Norman Campbell's definition of chance in terms of frequencies, Ramsey holds that "chances are degrees of belief within a certain system of beliefs and degrees of belief; not those of any actual person, but in a simplified system to which those of actual people, especially the speaker, in part approximate" (Ramsey 1990: 104). Such systems of beliefs typically contain empirical regularities. Chances differ from frequencies because the frequencies actually observed do not necessarily coincide with them; for instance the chance of a roulette hitting the 0 is the same irrespective of the fact that yesterday it never hit the 0 for the whole day. Unlike frequencies, chances are deemed objective in a twofold sense. In the first place, saying that a system includes a chance value referred to a given phenomenon means that the system itself cannot be made to include a pair of deterministic laws, ruling the occurrence and non-occurrence of the same phenomenon. Moreover, chances are objective "in that everyone agrees about them, as opposed e.g. to odds on horses" (Ramsey 1990: 106).

8 The related notion of probability in physics is then defined as chance referred to a more complex system which contains reference to scientific laws and theories. Physical probabilities represent ultimate chances, meaning that within the theoretical framework in which they belong there is no way of replacing them with deterministic laws. The assessment of physical probabilities, as well as their objective character, rests on scientific theories that are accepted by the scientific community. These are part of a 
strong system, supported by a good deal of evidence from experience. Ultimately, reference is made to the "true scientific system" which is "uniquely determined" because "long enough investigation will lead us all to it" (Ramsey 1990: 161). Notably, Ramsey's attitude in this connection echoes "Peirce's notion of truth as what everyone will believe in the end" (ibid.), as he puts it. A similar conception of truth was shared by James, whom is often mentioned in Ramsey's writings.

Ramsey takes a constructivist approach to knowledge centered on the notion of reliability. In the note Knowledge, he holds that a belief is knowledge if it is "formed in a reliable way. We say 'I know,' however, whenever we are certain, without reflecting on reliability. But if we did reflect then we should remain certain if, and only if, we thought our way reliable." (Ibid.: 110). A number of clues contained in other notes give an idea of the criteria for reliability Ramsey had in mind. They include, in the first place, experimentation, which is crucial for the formation of beliefs and the assessment of probabilities. In Ramsey's words: "Why should one experiment? To increase the weight of one's probabilities." (Ibid: 161). The note called Statistics calls attention to another important ingredient, namely statistics whose "significance is in suggesting a theory or set of chances" (ibid.: 102). Statistics is also the tool to perform causal analysis: "we find that chances are not what we expect, therefore the die is biased." (Ibid.: 103). In this way, knowledge is made to rest on the possibility of establishing a strong link between belief and success. As described by Nils-Eric Sahlin for Ramsey "a belief is knowledge if it is obtained by a reliable process and if it always leads to success" (Sahlin 1990: 93). ${ }^{9}$

That Ramsey's pragmatism was influenced by Peirce and James has been argued in some detail by a number of authors. ${ }^{10}$ Less emphasis has been placed on the influence of Poincaré, whose conception of chance was taken into serious consideration by Ramsey, as shown by a number of mentions in his notes. ${ }^{11}$ We also know that Ramsey read Mach's Analysis of Sensations and it is plausible to conjecture that the ideas spelled out in that book had an impact on him. Such a conjecture has been made by Sahlin, who considers Mach "may have had an unforeseen influence on Ramsey" (Sahlin 1990: 125). Note 15 in Notes on Philosophy, Probability and Mathematics, titled "On 'I can'," in which Ramsey comments on a passage from Mach's book, points in the same direction.

\section{Bruno de Finetti, Radical Probabilist}

11 Bruno de Finetti embraced an uncompromising version of subjectivism, which earned him the epithet "radical probabilist" coined by Richard Jeffrey. ${ }^{12}$ His probabilism was influenced in equal measure by the Italian pragmatists Mario Calderoni and Giovanni Vailati and the scientist-philosophers Ernest Mach and Henri Poincaré.

For de Finetti, pragmatism meant the opposite of the "hundred ways of not saying anything" (de Finetti 1976: 285) ${ }^{13}$ common to all philosophical trends from scholasticism to idealism, except for empiricism. He claims to have "adopted the mode of thinking advocated by authors like Vailati and Calderoni" because "it was precisely this form of reasoning which, in successive waves, from Galileo to Einstein, from Heisenberg to Born, freed physics - and with it the whole of science and human thought - from those superstructures of absurd metaphysical dross which had condemned it to endless round of quibbling about pretentious vacuities" (de Finetti 1975: 41). Similar statements recur many times in de Finetti's writings, which abound with attacks on metaphysics and 
realism, seen as contrary to a view of science as a product of human activity aimed primarily at prediction. In line with the mode of thinking of pragmatists, de Finetti rejects the "immutable and necessary" nature of scientific laws, in the conviction that "the absolute truth does not exist" and therefore "science, understood as the discoverer of absolute truths, remains idle for lack of absolute truths" (de Finetti 1989: 169). The refusal of such unrealizable ideals gives way to a deep concern for the applicability of science.

13 The application of science, and above all forecast, requires probability. Here, de Finetti appeals to Poincaré who "has clearly understood that only an accomplished fact is certain, that science cannot limit itself to theorizing about accomplished facts but must foresee, that science is not certain, and that what really makes it go is not logic but the probability calculus" (ibid.: 173). Right in the beginning of his most famous paper, namely La prévision: ses lois logiques, ses sources subjectives, containing the text of the lectures he gave in 1935 at the Institut Henri Poincaré in Paris, de Finetti calls Poincaré "the thinker who attributed the greatest domain of application to the theory of probability and gave it a completely essential role in scientific philosophy" (de Finetti 1980a: 59). Moreover, de Finetti praises Poincaré for "having used psychological analysis to put life back into some formally arid questions which it is not enough to consider only from the formal point of view" (de Finetti 1989: 219). The psychological element is obviously crucial for de Finetti, who advocates the subjective view and defines probability as the degree of belief "as actually held by someone, on the ground of his whole knowledge, experience, information" (de Finetti 1968: 45) in the occurrence of an event whose outcome is unknown. Probability is a primitive notion defined implicitly by the role it plays with respect to the decisional criterion of an individual; in other words the meaning of probability resides in its being our guide to prediction and action. Also in this regard de Finetti's attitude is patently close to pragmatism.

Importantly, de Finetti regards his own position as "analogous to Mach's positivism, where by 'positive fact' each of us means only his effective subjective impressions" (de Finetti 1989: 171). Mach is also mentioned as a source of inspiration in a letter of 1957 to the jurist and political scientist Bruno Leoni, in which de Finetti describes his own viewpoint as close to "scientific criticism (for instance Mach; 'operational definitions' in modern physics, 'behaviourism,' and so on) tracing back to the perspective of Hume, Berkeley, etc." ${ }^{14}$

Operationalism is, together with pragmatism and empiricism, a fundamental component of de Finetti's perspective, because in order to endow probability with effective import "it must not be based on vain or over-elaborate phrases, but it must be operative, i.e. based on the indications given by experiments, albeit conceptual ones, that must be carried out in order to measure it" (de Finetti 1976: 294). Most influential in that connection was Percy Bridgman's The Logic of Modern Physics (1927), which de Finetti read in the German edition titled Die Logik der heutigen Physik (1932), mentioned many times in his writings. The definition of probability in terms of betting quotients is by no means regarded as the only option by de Finetti, who in the 1931 paper Sul significato soggettivo della probabilità ${ }^{15}$ introduced an alternative definition based on the qualitative relation "at least as probable as," and from the sixties onwards preferred to adopt scoring rules of the Brier kind. Named after the meteorologist who applied it to weather forecasts, such a rule serves the twofold purpose of obliging probability evaluators to be as accurate as possible and improve evaluations, made both by single agents and groups, by providing them with a 
tool apt to enhance "self-control" as well as "comparative control" (de Finetti 1980b: 1151). ${ }^{16}$

The idea of improving probability evaluation is far from being alien to the subjective viewpoint, in spite of the widespread misunderstanding whereby subjectivism is some sort of an "anything goes" approach, according to which in no way can probability judgments can be judged right or wrong, once coherence is satisfied. ${ }^{17}$ Such a misunderstanding has obviously been suggested by de Finetti's assertion that "probability does not exist" printed in capital letters in the preface to the English edition of Teoria delle probabilità. ${ }^{18}$ De Finetti's claim has been taken to mean that probability evaluations, as the expression of personal feelings, can be made without taking into account empirical evidence. On the contrary, the assertion was meant to reject the metaphysical tenet that probability is an objective feature of phenomena. However, while objecting to metaphysics, de Finetti firmly insisted that empirical evidence is an essential ingredient of probability assessment that must not be neglected. He makes it clear that the evaluation of probability "depends on two components: (1) the objective component, consisting of the evidence of known data and facts; and (2) the subjective component, consisting of the opinion concerning unknown facts based on known evidence" (de Finetti 1974: 7). The effectiveness of subjective probability as a tool for prediction can and must be assessed, and the criterion for it is the success of forecasts. As de Finetti puts it: "though maintaining the subjectivist idea that no fact can prove or disprove belief I find no difficulty in admitting that any form of comparison between probability evaluations (of myself, of other people) and actual events may be an element influencing my further judgment, of the same status as any other kind of information." (de Finetti 1962: 360). In other words, de Finetti took very seriously the problem of objectivity, or the "goodness" of probability evaluations, and actively worked on the topic, partly in collaboration with Jimmie Savage, pioneering a thriving field of research. ${ }^{19}$

17 If the emphasis on successful prediction is perfectly in tune with pragmatism, so is de Finetti's result known as the "representation theorem," which secures to subjective probability applicability to statistical inference. In brief, the representation theorem states that the adoption of the Bayesian method in conjunction with exchangeability ensures the convergence between degrees of belief and frequencies. Such a convergence offers the grounds for the reduction of objective to subjective probability, because once it is made clear how information on frequencies interacts with subjective elements, there is no need for objective probabilities (chances). The pragmatic meaning of this move has been stressed by Brian Skyrms, who observes that "de Finetti does not offer a translation of chance. Rather, he looks at the role that chance plays in standard statistical reasoning, and argues that that role can be fulfilled perfectly well without the metaphysical assumption that chances exist" (Skyrms 1984: 12). Furthermore, de Finetti thinks that the representation theorem answers the problem of induction, because it justifies "why we are also intuitively inclined to expect that frequency observed in the future will be close to frequency observed in the past" (de Finetti 1972: 34). Once again, the argument is pragmatical, as it is based on the role of induction, which amounts to guiding our reasoning and decision. ${ }^{20}$

Although de Finetti's fierce opposition to the notion of chance marks a divergence with Ramsey's subjectivism, it must be added that late in his life de Finetti softened his attitude somewhat, admitting that probability evaluations deriving from accepted scientific theories have a more robust meaning than those not supported by such a strong 
evidence, thereof coming close to Ramsey's position. Unlike Ramsey, who - as we saw developed the idea, de Finetti did not go beyond the admission that probability evaluations constrained by scientific theories - for instance the distributions belonging to statistical mechanics - "provide more solid grounds for subjective opinions" (de Finetti 2008: 52). ${ }^{21}$ To this he adds that "by looking at the outcome of a phenomenon we could be driven to formulate a rule by virtue of which, in each case, things would blend in that way, as if it were a necessary law of nature" (ibid.). This claim highlights de Finetti's conviction that scientific laws are rules, or instruments for prediction and action; in his colorful prose: "if one takes science seriously, then one always considers it also as an instrument. Otherwise, what would it amount to? Building up houses on cards, empty of any application whatsoever!" (Ibid.: 53). The author's position regarding scientific laws and theories goes hand in hand with the conviction that there is a continuity between science and everyday life. Also in that connection there is a patent affinity between de Finetti's position and pragmatism.

\section{5. Émile Borel, Temperate Subjectivist ${ }^{22}$}

19 In a review of Keynes's Treatise on Probability (1921) published in 1924 in Revue philosophique and reprinted as an appendix in the monograph Valeur pratique et philosophie des probabilités (1939), , ${ }^{23}$ Borel moves a number of objections to Keynes, and outlines a view of probability that shares some aspects of both subjectivism and pragmatism and is in various ways influenced by Poincaré. To Borel's eyes, Keynes overlooked the application of probability to science, for concentrating on the probability of judgments. Starting from the consideration that "the probability that an atom of radium will explode tomorrow is, for the physicist, a constant of the same kind as the density of copper or the atomic weight of gold. Albeit these constants are always at the mercy of the progress of physicalchemical theory, they are constants in the present state of science" (Borel 1964: 50), Borel concludes that probability has a different meaning in different contexts. In particular, probability has a different meaning depending on the body of information available within the context in which it occurs. In science, where its assessment is backed by laws accepted by the scientific community, probability has a more objective value than in everyday life, where it can take "different values for different individuals" (ibid.). It is important to clarify what "objective" means for Borel. As he puts it: "objective probabilities can be defined as probabilities whose value is the same for a certain number of individuals who are well informed of the conditions of the aleatory event." (Borel 1952: 105). In other words, the objectivity of probabilities occurring in science derives from the theories accepted by the community of scientists, and as such are supported by a good deal of evidence. The similarity with Ramsey's notion of objective probability is striking. Poincaré's conception of objective chance as having intersubjective character ${ }^{24}$ is also likely to have exerted an influence upon Borel's views on the matter.

20 As concerns single case probability assignments, Borel maintains that "the probability of a single case is defined subjectively by the conditions at which an agent is ready to accept to bet on the occurrence or non-occurrence of the event" (Borel 1952: 105). In this connection he takes sides with subjectivists and mentions de Finetti's La prévision. The betting method is taken to provide the operative tool that allows probability to be connected with action, since it "can be applied to all verifiable judgments; it allows for a numerical evaluation of probabilities with a precision quite comparable to that with 
which one evaluates prices" (Borel 1964: 57). Bridging the gap between probability and action is deemed crucial by Borel, who strongly advocates the importance of practice, and embraces the pragmatist principle that "a proposition has practical interest for men only insofar as it can exercise an influence on their actions" (1952: 89).

While borrowing such a principle from Reichenbach, ${ }^{25}$ Borel makes it clear that agreement does not extend to the frequency approach, against which he raises a few objections. In particular, he criticizes Reichenbach's treatment of the single case by observing that imposing a requirement of homogeneity to the reference class would lead to considering increasingly narrow classes, ending up with "classes that contain so few elements that the concept of frequency does no longer apply" (ibid.: 87). The more detailed is the description of the single case, the more evident the differences with other instances of the same kind, so that "one will find that probability is defined in a way that is less and less precise, the better known is the case at hand" (ibid.: 88).

As already observed, Borel takes a subjective approach to the estimation of single case probabilities, which he reckons crucial in view of practical applications. While endorsing the subjective approach, he does not overlook the importance of frequencies nor does he deny that they are a fundamental component of probability evaluation; rather he holds that in some contexts other elements come into play. To exemplify his position, Borel invites us to consider the case of a medical doctor who is asked to make a forecast about the probability of survival of a patient who has contracted a certain disease. The doctor will consider the relevant statistics of deaths among patients affected by the same illness, but he is also likely to consider additional information regarded to be relevant to the case at hand, in the light of his own experience. Like de Finetti, for Borel single case probability attributions result from the concurrence of information on frequencies, personal experience and common sense. In a note titled Punti di vista: Émile Borel de Finetti praises Borel for holding that probability must be referred to the single case and can be measured sufficiently well by means of the betting method, but criticizes his eclectic attitude according to which probability can take an objective as well as a subjective value. ${ }^{26}$ As we saw, Borel feels the need to address the issue of defining an objective notion of probability suitable for application to science, putting forward a solution having some similarity with Ramsey's and Poincaré's. To sum up, Borel's subjectivism has much in common with de Finetti's but is more moderate, mainly due to his tenet that probability assessments made in the context of disciplines like physics, endowed with theories shared by scientists, have an objective character. However, it must be stressed that his view of objective probability does not have a realistic import, being rather close to the pragmatist idea of objectivity as agreement of the scientific community.

Borel's commitment to the subjective interpretation goes hand in hand with a probabilistic approach to epistemology inspired by the conviction that "probability lays at the core of scientific knowledge" because "the value of all scientific results can be assessed only by means of a probability coefficient" (Borel 1952: 10). ${ }^{27}$ Moreover, "the theory of probability not only possesses the same practical and philosophical value of all of other scientific theories; but is the basis of all knowledge" (Borel 1952: 11). The crucial importance of probability is given by its practical value, which "surpasses that of the rest of human knowledge" (ibid:: 42). Borel's deep concern for the practical value of probability is not confined to science, but extends to all aspects of life, including everyday life, which is regarded on a par with science, in line with the pragmatist perspective. 


\section{Concluding Remarks}

24

Although - as already observed - other authors contributed to the birth of subjective probability, Borel, Ramsey and de Finetti played a key role in its formation. In addition to the subjective approach to probability, these authors shared a view of epistemology grounded in the conviction that science and knowledge in general are deeply probabilistic in nature. Such a viewpoint is imbued with ideas that are ingrained in the pragmatist tradition, including the tenet that the main purpose of science is prediction and success is the canon for the justification of induction; the overall importance ascribed to practice; and the emphasis on action, regarded as the gist of the meaning and the value of probability. These ideas were inspired partly by American pragmatists and partly by European scientist-philosophers like Mach and Poincaré, who were a formidable source of inspiration for the mathematicians and scientists of their time, including those working on the foundations of probability.

\section{BIBLIOGRAPHY}

BACKHURST David, (2017), "The Spirit of Pragmatism in the Quads of Oxford," in Cheryl Misak \& Huw Price (eds), The Practical Turn: Pragmatism in Britain in the Long Twentieth Century, 75-90. BOREL Émile, (1952 [1939]), "Valeur pratique et philosophie des probabilités," in Traité du calcul des probabilités et ses applications (1925-1939), 4 (3), Paris, Gauthier-Villars. (Translation of passages quoted in the text is mine.)

BOREL Émile, (1964 [1924]), “Apropos of a Treatise on Probability,” in Henry Ely Kyburg \& Howard Edward Smokler (eds), Studies in Subjective Probability, New York, Wiley, 47-60.

BOREL Émile, (2014 [1907]), “An Economic Paradox: The Sophism of the Heap of Wheat and Statistical Truths," Erkenntnis, 79, 1081-8.

BRIDGMAN Percy, (1927), The Logic of Modern Physics, New York, MacMillan.

CALDERoni Mario \& Giovanni vailati, (2009 [1909]), "Pragmatism and the Various Ways of Saying Nothing," in Claudia Arrighi, Paola Cantù, Mauro De Zan \& Patrick Suppes (eds), Logic and Pragmatism. Selected Essays by Giovanni Vailati, Stanford, CSLI Publications, 249-59.

DAWID Philip A. \& Maria Carla GALAVotTI, (2009), “De Finetti's Subjectivism, Objective Probability, and the Empirical Validation of Probability Assessments," in Maria Carla Galavotti (ed.), Bruno de Finetti, Radical Probabilist, London, College Publications, 97-114.

DE FINETTI Bruno, (1939), “Punti di vista: Émile Borel," Supplemento Statistico ai Nuovi problemi di Politica, Storia, Economia, 5, 61-71.

DE FINETTI Bruno, (1962), “Does it Make Sense to Speak of 'Good Probability Appraisers'?,” in Irving John Good, Alan James Mayne \& John Maynard Smith (eds), The Scientist Speculates. An Anthology of Partly-Baked Ideas, New York, Basic Books, 357-64. 
DE FINETTI Bruno, (1968), “Probability: the Subjectivistic Approach,” in Raymond Klibansky (ed.), La philosophie contemporaine, Florence, La Nuova Italia, 45-53.

DE FINETTI Bruno, (1972), “Subjective or Objective Probability: is the Dispute Undecidable?," Symposia Mathematica, 9, 21-36.

DE FINETTI Bruno, (1974), “The Value of Studying Subjective Evaluations of Probability," in CarlAxel Stäel von Holstein (ed.), The Concept of Probability in Psychological Experiments, DordrechtBoston, Reidel, 1-14.

DE FINETTI Bruno, (1975 [1970]), Theory of Probability, New York, Wiley.

DE FINETTI Bruno, (1976), “Probability: Beware of Falsifications!,” Scientia, 70 (3), 283-303.

DE FINETTI Bruno, (1980a [1937]), “Foresight: Its Logical Laws, Its Subjective Sources," in Henry E. Kyburg \& Howard E. Smokler (eds), Studies in Subjective Probability, Huntington, N.Y., Krieger, 57-118.

DE FINETTI Bruno, (1980b), "Probabilità," in Enciclopedia Einaudi, Torino, Einaudi, 1146-87.

DE finetTi Bruno, (1989 [1931]), “Probabilism," Erkenntnis, 31 (2-3), 169-223.

DE FINETTI Bruno, (1992 [1931]), “On the Subjective Meaning of Probability,” in Paola Monari \& Daniela Cocchi (eds), Bruno de Finetti: Probabilità e induzione (Induction and Probability), Bologna, CLUEB, 298-329.

DE FINETTI Bruno, (2008 [1995]), Philosophical Lectures on Probability, ed. by Alberto Mura, Dordrecht, Springer.

DOKIC Jérôme \& Pascal ENGEL, (2002 [2001]), Frank Ramsey. Truth and Success, London-New York, Routledge.

Galavotti Maria Carla, (1989), “Anti-realism in the Philosophy of Probability: Bruno de Finetti's Subjectivism," Erkenntnis, 31 (2-3), 239-62.

GALAVotTi Maria Carla, (1995), “F. P. Ramsey and the Notion of 'Chance'," in Jaakko Hintikka \& Klaus Puhl (eds), The British Tradition in the 20th Century Philosophy. Proceedings of the 17th International Wittgenstein Symposium, Vienna, Hölder-Pichler-Tempsky, 330-40.

GALAVOTTI Maria Carla, (1999), “Some Remarks on Objective Chance (F. P. Ramsey, K. R. Popper and N. R. Campbell)," in Maria Luisa Dalla Chiara, Roberto Giuntini \& Federico Laudisa (eds), Language, Quantum, Music, Dordrecht-Boston, Kluwer, 73-82.

GALAVOTTI Maria Carla, (2003), “Harold Jeffreys' Probabilistic Epistemology: Between Logicism and Subjectivism," British Journal for the Philosophy of Science, 54, 43-57.

Galavotti Maria Carla, (2005), Philosophical Introduction to Probability, Stanford, CSLI Publications. GALAVotTi Maria Carla, (2008), “A Tribute to Janina Hosiasson Lindenbaum: a Philosopher Victim of the Holocaust," in Robero Scazzieri \& Raffaella Simili (eds), Migration of Ideas, Sagamore Beach, Watson, 179-94.

Galavotтi Maria Carla, (2011), "Probability and Pragmatism," in Dennis Dieks, Wenceslao Gonzalez, Stephan Hartmann, Thomas Uebel \& Marcel Weber (eds), Explanation, Prediction, and Confirmation, Dordrecht, Springer, 499-510.

Galavotti Maria Carla, (2014a), "Probabilistic Epistemology: A European Tradition," in Maria Carla Galavotti, Elisabeth Nemeth \& Friedrich Stadler (eds), Philosophy of Science in Europe; European Philosophy of Science, Dordrecht, Springer, 77-88. 
GALAVotTI Maria Carla, (2014b), "New Prospects for Pragmatism: Ramsey's Constructivism," in Maria Carla Galavotti, Dennis Dieks, Wenceslao Gonzalez, Stephan Hartmann, Thomas Uebel \& Marcel Weber (eds), New Directions in the Philosophy of Science, Dordrecht, Springer, 645-56.

GalavotTi Maria Carla, (2017a), “The Ghost of Pragmatism. Some Historical Remarks on the Debate on the Foundations of Probability," in Sami Pihlström, Friedrich Stadler \& Niels Weidtmann (eds), Logical Empiricism and Pragmatism, Cham, Springer International Publishing, $167-82$.

Galavotti Maria Carla, (2017b), “On Some French Probabilists of the Twentieth Century: Fréchet, Borel, Lévy," in Hannes Leitgeb, Ilkka Niiniluoto, Päivi Seppälä \& Elliot Sober (eds), Logic, Methodology and Philosophy of Science - Proceedings of the 15th International Congress, London, College Publications, 155-73.

Galavotti Maria Carla, (2018), "Who is Afraid of Subjective Probability?," in Ciro de Florio \& Alessandro Giordani (eds), From Arithmetic to Metaphysics, Berlin/Boston, De Gruyter, 151-7. JEFFREY Richard C., (1992), “Radical Probabilism (Prospectus for a User's Manual)," in Enrique Villanueva (ed.), Rationality in Epistemology, Atascadero, Cal., Ridgeview, 193-204.

MISAK Cheryl, (2016), Cambridge Pragmatism, Oxford, Oxford University Press.

MISAK Cheryl, (2017), “Ramsey's 1929 Pragmatism,” in Cheryl Misak \& Huw Price (eds), The Practical Turn: Pragmatism in Britain in the Long Twentieth Century, Oxford, Oxford University Press, 11-28.

MISAK Cheryl \& Huw PRICE (eds), (2017), The Practical Turn: Pragmatism in Britain in the Long Twentieth Century, Oxford, Oxford University Press.

PIHLSTRÖM Sami, STADLER Friedrich \& Niels WEIDTMANN (eds), (2017), Logical Empiricism and Pragmatism, Cham, Springer International Publishing.

RAMSEY Frank Plumpton, (1990), Philosophical Papers, ed. by David Hugh Mellor, Cambridge, Cambridge University Press.

RAMSEY Frank Plumpton, (1991), Notes on Philosophy, Probability, and Mathematics, ed. by Maria Carla Galavotti, Naples, Bibliopolis.

REICHENBACH Hans, (1937), "Les fondements logiques du calcul des probabilités," Annales de l'Institut Henri Poincaré, 7, part 5, 267-348.

Romizi Donata, (2017), “Classical Pragmatism and Metaphysics: James and Peirce on Scientific Determinism," in Sami Pihlström, Friedrich Stadler \& Niels Weidtmann (eds), Logical Empiricism and Pragmatism, Cham, Springer International Publishing, 43-66.

SAHLIN Nils-Eric, (1990), The Philosophy of F. P. Ramsey, Cambridge, Cambridge University Press. SKYRMS Brian, (1984), Pragmatics and Empiricism, New Haven, Yale University Press.

THAYER Horace Standish, (1968), Meaning and Action. A Critical History of Pragmatism, Indianapolis, Bobbs Merrill.

TIERCELIN Claudine, (2004), “Ramsey’s Pragmatism,” Dialectica, 58 (4), 529-47.

WIENER Philip P., (1973), "Pragmatism," in Id. (ed.), Dictionary of the History of Ideas, New York, Charles Scribner's Sons, volume III, 551-70. 


\section{NOTES}

1. For more details see Galavotti 2017a.

2. Evidence that in Europe ideas close to pragmatist philosophy were around before the encounter with American pragmatism has been disclosed by a number of authors including Friedrich Stadler, Thomas Uebel, Donata Romizi and Massimo Ferrari; see their chapters in Pihlström, Stadler \& Weidtmann (eds) 2017.

3. More on this is to be found in Galavotti 2011.

4. The reader interested in Hosiasson's contribution to the philosophy of probability (largely overlooked by the literature) is addressed to Galavotti 2008. More to be found in Galavotti 2014a, where the work of Hosiasson, together with that of the other authors discussed here, is located within a larger European trend in probabilistic epistemology, which anticipated of a few decades the tendency today predominant in philosophy of science.

5. On Harold Jeffreys's probabilistic epistemology see Galavotti 2003 and 2005.

6. Ramsey's pragmatism has been discussed among others by Philip Wiener 1973, Horace Standish Thayer 1968, Nils-Eric Sahlin 1990, Jérôme Dokic \& Pascal Engel 2002, Claudine Tiercelin 2004, Cheryl Misak 2016 and 2017.

7. In Galavotti 2011 attention is called to the influence of pragmatism on Ramsey's conception of probability.

8. See Galavotti 2005 for a more extensive treatment of Ramsey's subjectivism, and Galavotti 1995 and 1999 for more on his notion of chance.

9. Ramsey's constructivism is dealt with in some detail in Galavotti $2014 \mathrm{~b}$.

10. See footnote 6 .

11. See Ramsey's note "Chance" and notes 67 and 69, which is titled "Poincaré's Essay on Chance in Science and Method," in Ramsey 1991.

12. See Jeffrey 1992.

13. De Finetti refers to the title of an essay by Calderoni and Vailati which appeared in 1909 - for the English translation see Calderoni \& Vailati 2009.

14. Quoted from document BD 10-13-27 of the "Bruno de Finetti Collection," with the permission of the University of Pittsburgh. All rights reserved.

15. English edition in de Finetti 1992.

16. See Dawid \& Galavotti 2009 for more details.

17. For a rebuttal of such misunderstanding see Galavotti 2018.

18. See de Finetti 1975.

19. For more details see Dawid \& Galavotti 2009.

20. See Galavotti 1989 for a more extensive treatment of the connections between de Finetti's anti-realism, operationalism and pragmatism.

21. The quotation is from Philosophical Lectures on Probability, which contains the English translation of a series of lectures delivered by de Finetti in 1979, see de Finetti 2008.

22. Some passages of this section are borrowed from Galavotti $2017 \mathrm{~b}$.

23. The monograph is the last one of a series of eighteen forming the Traité $d u$ calcul des probabilités et ses applications, published between 1925 and 1939. For the English version of Borel's review of Keynes's Treatise see Borel 1964.

24. On this issue see Romizi 2017.

25. Borel refers to Reichenbach 1937.

26. See de Finetti 1939.

27. See also Borel 2014 where the author addresses the "sophism of the heap of wheat" suggesting a way out of it based on probability. 


\section{ABSTRACTS}

Pragmatism, taken not just as a philosophical movement but as a way of addressing problems, strongly influenced the debate on the foundations of probability during the first half of the twentieth century. Upholders of different interpretations of probability such as Hans Reichenbach, Ernest Nagel, Rudolf Carnap, Frank Ramsey, and Bruno de Finetti, acknowledged their debt towards pragmatist philosophers, including Charles Sanders Peirce, William James, Clarence Irving Lewis, William Dewey and Giovanni Vailati. In addition, scientist-philosophers like Ernst Mach, Ludwig Boltzmann, Henri Poincaré, Pierre Duhem, and Karl Pearson, who heralded a conception of science and knowledge at large that was close to pragmatism, were very influential in that debate. Among the main interpretations of probability - frequentism, propensionism, logicism and subjectivism -, the latter is no doubt the closest to the pragmatist outlook. This paper concentrates on three representatives of the subjective theory, namely Frank Ramsey, Bruno de Finetti and Émile Borel.

\section{AUTHOR}

\section{MARIA CARLA GALAVOTTI}

Università di Bologna

mariacarla.galavotti[at]unibo.it 